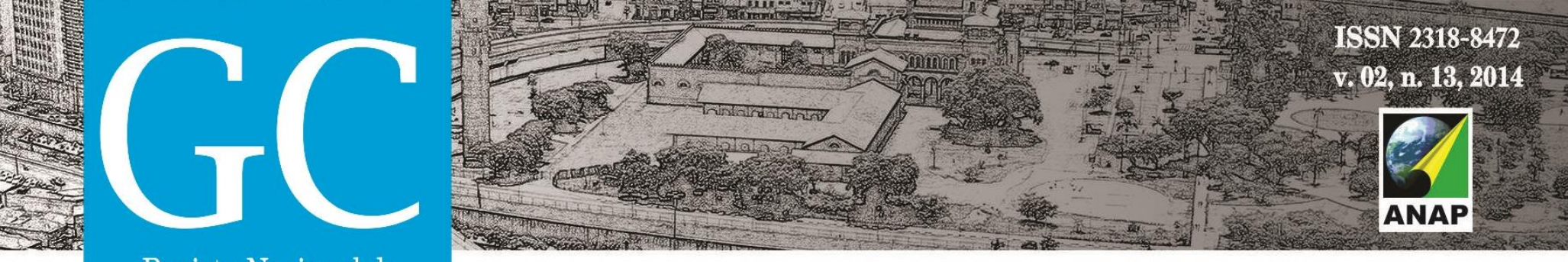

Revista Nacional de

Gerenciamento de Cidades

\title{
AS DIFERENTES FORMAS DE EXPANSÃO URBANA
}

\author{
Luana Andressa Teixeira Japiassú ${ }^{1}$
}

Regina Dulce Barbosa Lins ${ }^{2}$

\begin{abstract}
RESUMO
Este artigo tem como objetivo descrever as diferentes formas nas quais o processo de expansão urbana se apresenta no tecido urbano. Primeiro discute-se o conceito de expansão urbana demonstrando o caminho percorrido até encontrar as sete formas em que o processo se apresenta no tecido urbano. Então, chega-se num conceito operacional para expansão urbana: crescimento territorial urbano. Será mostrado, também, que existem dois grandes tipos de crescimento territorial urbano, o intensivo e o extensivo, que se distinguem em suas características, causas e consequências. Cada um dos tipos possui formas diferentes de se apresentarem no tecido urbano. É importante conhecer as formas de expansão urbana para ajudar a entender como o processo acontece nas cidades, servindo como base para o planejamento da mesma. Como resultado chegouse a representações gráficas das formas de expansão urbana que ajudam a identifica-las empiricamente nas cidades.
\end{abstract}

PALAVRAS-CHAVE: Expansão urbana. Crescimento territorial urbano. Tipos e formas.

\section{THE DIFFERENT FORMS OF URBAN EXPANSION}

\section{ABSTRACT}

This article aims to describe the different ways in which the process of urban expansion presents itself in the urban tissue. First, it is discussed the concept of urban expansion demonstrating the path to find the seven forms at which the process presents itself at the urban tissue. The, it is achieved an operational concept for urban expansion: urban territorial growth. It will also be shown that there are two major types of urban territorial growth, the intensive and the extensive, which differ from each other in their characteristics, causes and consequences. Each type has different ways of presenting themselves in the urban tissue. It is important to

\footnotetext{
${ }^{1}$ Mestranda em Arquitetura e Urbanismo, DEHA/UFAL. luanajapiassu@hotmail.com.

${ }^{2}$ PhD em Estudos Urbanos, DEHA/UFAL Professora Associada 4. reginalins.br@gmail.com.
} 


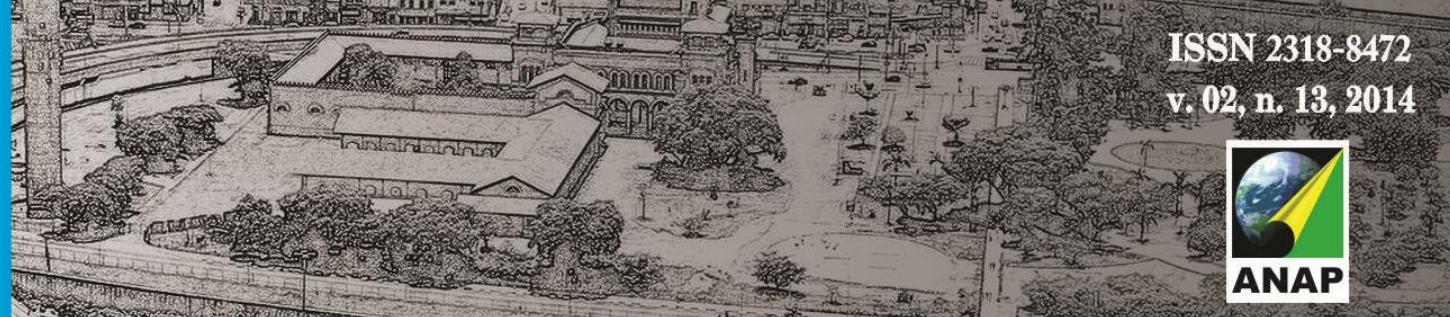

Revista Nacional de

Gerenciamento de Cidades

know the ways of urban expansion to help understanding how the process happens in cities, serving as the foundation for planning them. As a result, this study has reached graphical representations of urban expansion shapes that help identify them empirically in the cities.

KEY-WORDS: Urban expansion. Urban territorial growth. Types and forms.

\section{LAS DIFERENTES FORMAS DE EXPANSIÓN URBANA}

\section{RESUMEN}

Este artículo tiene el objetivo de describir las diferentes formas que el proceso de expansión urbana se presenta en el tejido urbano. Em primer lugar es analizado el concepto de expansión urbana, que nos enseña el camino para encontrar las siete formas en que el proceso se presenta en el tejido urbano. Luego, llegamos a un concepto operacional para la expansión urbana: crecimiento territorial urbano. Serán presentados también los dos tipos principales de crecimiento territorial urbano, el intensivo y el extensivo, que se difieren en sús caracteristicas, causas y consequencias. Cada tipo tiene diferentes formas de presentación en el tejido urbano. Es importante conocer las formas de expansión para ayudar a compreender cómo ocurre el processo en las ciudades y también porque sirve de base para la planificación de la misma. Los resultados fueron representaciones gráficas de las formas de expansión urbana que ayudan a identificarlas empiricamente en las ciudades.

PALABRAS-CLAVE Expansión urbana. Crecimiento territorial urbano. Tipos y formas.

\section{INTRODUÇÃO}

Expansão urbana é um processo que se refere às dinâmicas da cidade que resultam ou justificam seu crescimento. O conceito de expansão urbana pode ser operacionalizado, para esta pesquisa, pelo termo "crescimento territorial urbano". O processo pode ser dividido em dois grandes tipos em função de seu resultado em termos de ocupação do solo, crescimento territorial urbano intensivo e extensivo. $O$ crescimento territorial urbano intensivo tem como característica principal a intensificação do uso e ocupação do solo e o crescimento territorial urbano extensivo, a extensão do tecido urbano.

Cada um desses tipos possuem formas distintas de se apresentarem no tecido da cidade. $\mathrm{O}$ objetivo deste artigo é descrever as diferentes formas que o crescimento territorial urbano se apresenta no tecido urbano. Dessa forma, este artigo se estrutura da seguinte maneira: (i) discute-se o conceito do processo de 



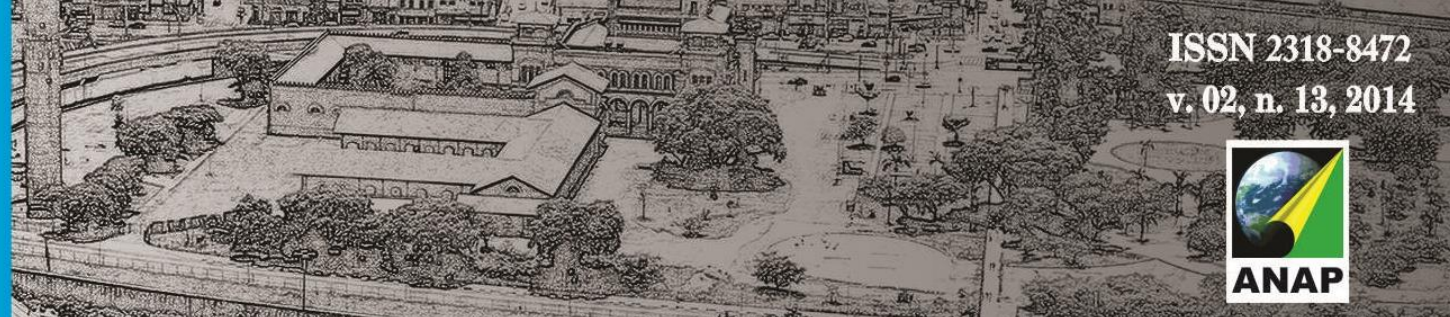

Revista Nacional de

Gerenciamento de Cidades

Entretanto a intensificação da ocupação do solo não ocorre apenas pela verticalização. Abramo (2007, p.35) aponta os assentamentos precários e a substituição familiar ou de usos como fator de adensamento dos centros urbanos, e não a verticalização. $E$, ainda, desmembramentos e a implantação de novas etapas de parcelamento do solo em loteamentos já existentes (COSTA, 2005, p.4). A fragmentação e/ou extensão das unidades residenciais para fins de comercialização ou locação, diminuem cada vez mais a dimensão do espaço urbano utilizado pelas famílias, intensificando o uso do solo. Esse processo será nomeado aqui por crescimento territorial urbano intensivo.

Figura 4: Esquema de expansão vertical e horizontal.

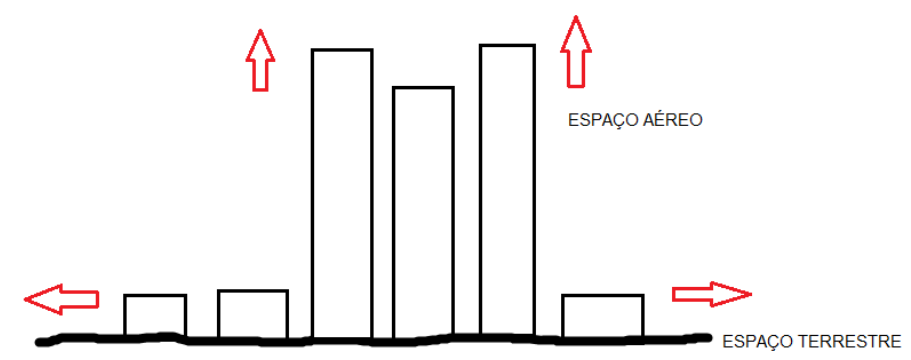

O crescimento territorial urbano sempre será um processo extensivo ou intensivo, no entanto pode ocorrer de formas distintas. Para as cidades brasileiras, encontraram-se sete formas distintas de crescimento territorial urbano na literatura.

\section{FORMAS DE CRESCIMENTO TERRITORIAL URBANO}

O crescimento territorial urbano intensivo segue duas formas: central ou periférico. O modelo de crescimento intensivo central (ver fig. 5) caracteriza-se pela alta densidade ocupacional em centros urbanos. A intensificação da ocupação do solo ocorre por meio da verticalização e pela fragmentação ou extensão das unidades residenciais em assentamentos populares. Já o modelo de crescimento intensivo periférico (ver fig. 6) ocorre nas periferias da cidade, às margens do centro urbano, mas pelos mesmos meios que o crescimento territorial intensivo central. 


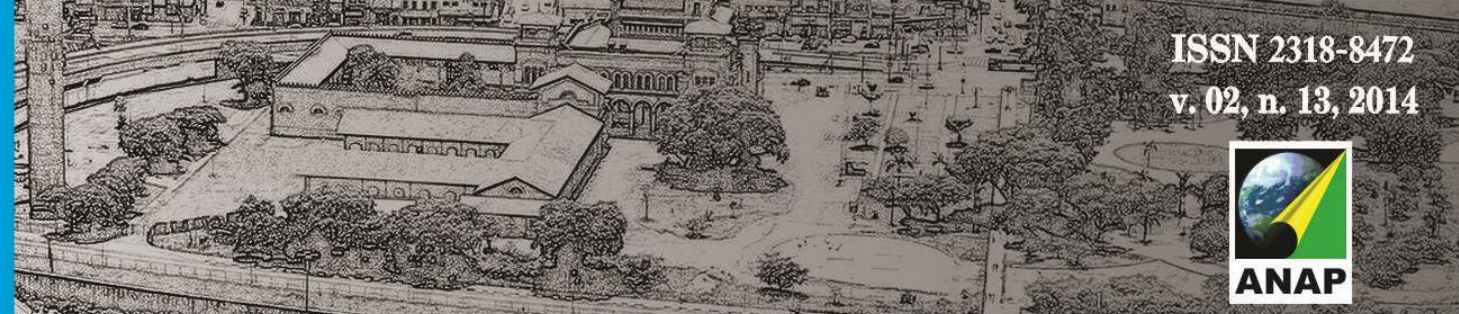

Revista Nacional de

Gerenciamento de Cidades

Figura 5: Esquema de expansão, crescimento intensivo central.

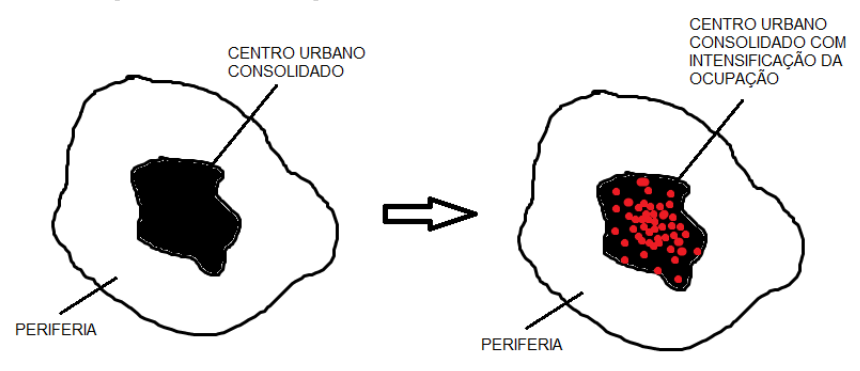

Figura 6: Esquema de expansão, crescimento intensivo periférico.
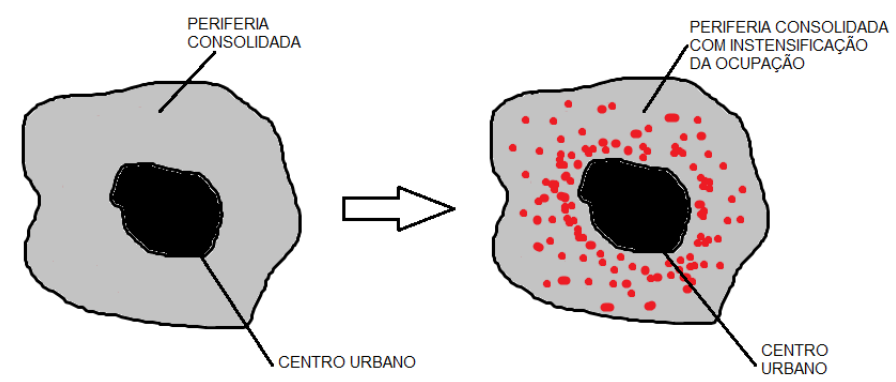

Por sua vez, o crescimento territorial urbano extensivo segue cinco modelos: (i) por dispersão urbana, (ii) por difusão urbana, (iii) pela soma de novas áreas à mancha urbana, (iv) tentacular e (v) por anéis concêntricos. O modelo de crescimento extensivo por dispersão urbana (ver fig. 7) caracteriza-se pela dispersão de núcleos urbanos secundários integrados por sistemas viários que os conectam com o centro urbano e entre si (BENTES, 2010, p.1). Os núcleos urbanos secundários caracterizam-se pela diversidade de usos, mas numa escala menor do que os que se encontram nos centros urbanos (LIMONAD, 2011, p.39).

Figura 7: Esquema de expansão, crescimento extensivo por dispersão urbana.

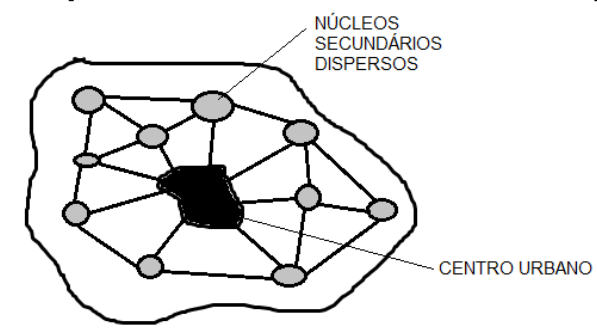

A forma de crescimento extensivo por difusão urbana caracteriza-se pela propagação de aglomerados urbanos unicamente residenciais, dependentes dos 


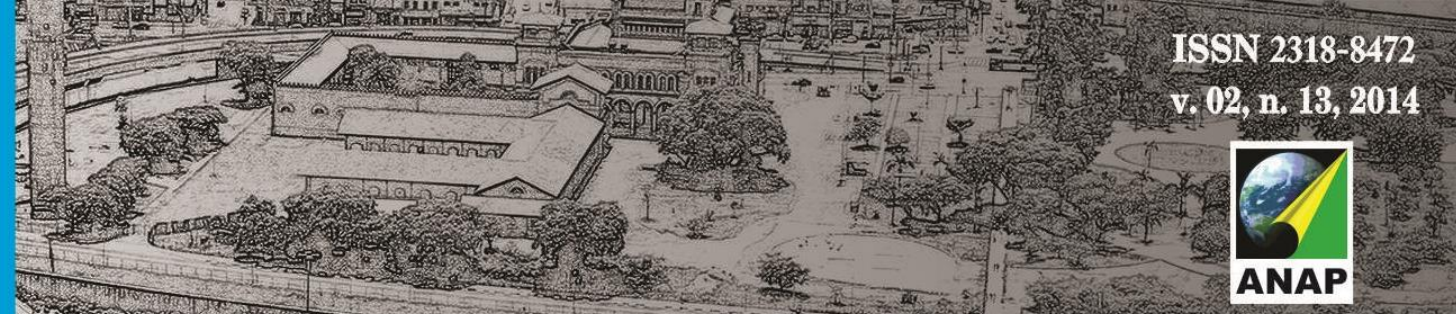

Revista Nacional de

Gerenciamento de Cidades

centros urbanos. A difusão urbana ocorre pelo "fracionamento de glebas na periferia das cidades (...) cuja característica principal nas grandes cidades latino-americanas é a inexistência (ou precariedade) de infra-estruturas, serviços e acessibilidade urbana" (ABRAMO, 2007, p.34).

O crescimento extensivo pela soma de novas áreas à mancha urbana (ver fig. 9) trata-se da adição de áreas ao tecido urbano. Esse modelo caracteriza-se principalmente pela transição de terras de uso rural para urbano, que acontece via parcelamento do solo (PEIXOTO, 2005, p.3), alteração no perímetro urbano (NASCIMENTO; MATIAS, 2011, p.71) ou criação/surgimento de novos bairros (SANTOS, 2012, p.265).

Figura 8: Esquema de expansão, crescimento extensivo por difusão urbana.

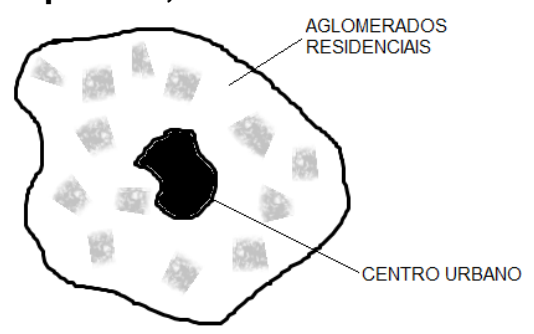

Figura 9: Esquema de expansão, crescimento extensivo pela soma de novas áreas à mancha urbana.

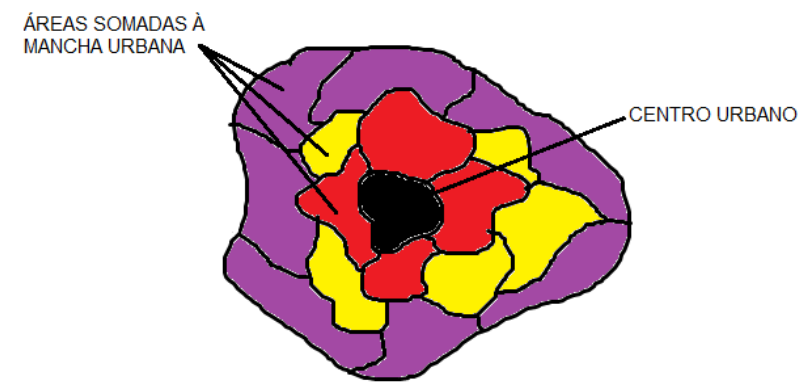

O modelo de crescimento extensivo tentacular (ver fig. 10) caracteriza-se pela ocupação das terras em função do sistema viário. A ocupação do espaço urbano acompanha as principais vias de acesso da cidade, que constituem verdadeiros vetores do crescimento territorial urbano (BRITO; SOUZA, 2005, p.54).

Figura 10: Esquema de expansão, crescimento extensivo tentacular. 


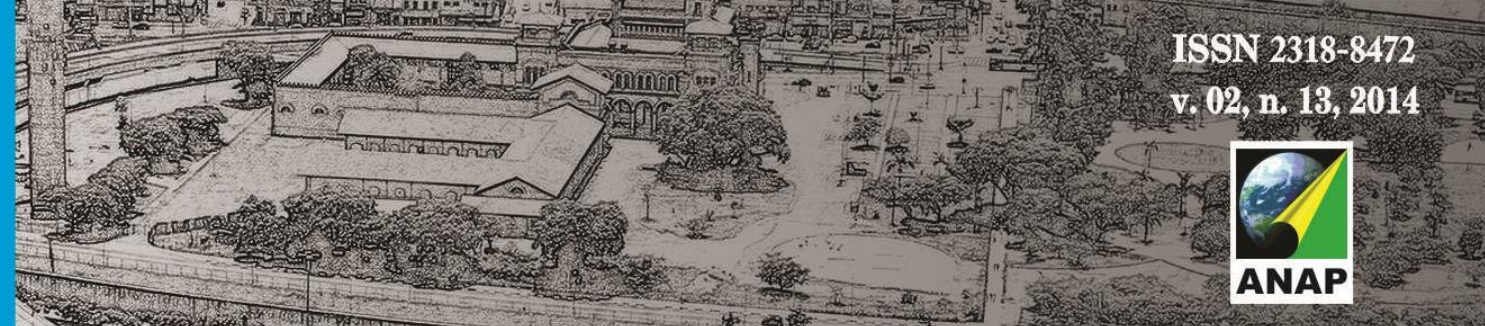

Revista Nacional de

Gerenciamento de Cidades

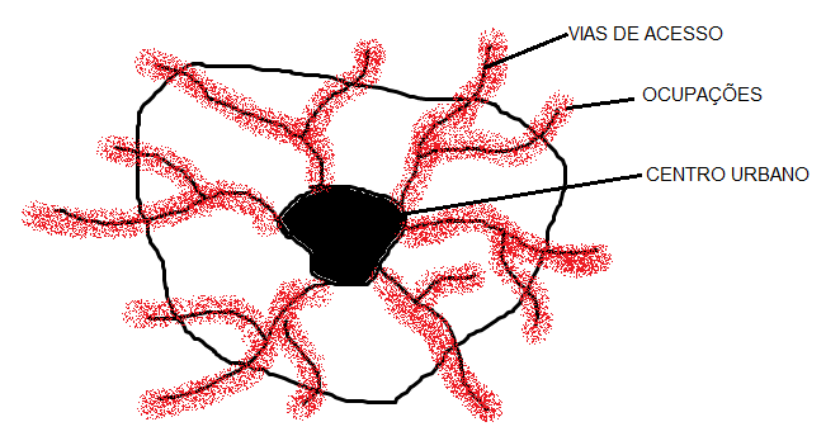

O modelo de crescimento extensivo por anéis concêntricos apresenta um crescimento radial em função de um centro (PORTELLA, et al, 2013, p.7). Essa disposição facilita o acesso ao centro urbano e acontece devido à característica polarizada referente ao centro urbano. A ocupação ocorre em camadas ao redor do centro urbano.

Figura 11: Esquema de expansão, crescimento extensivo anéis concêntricos.

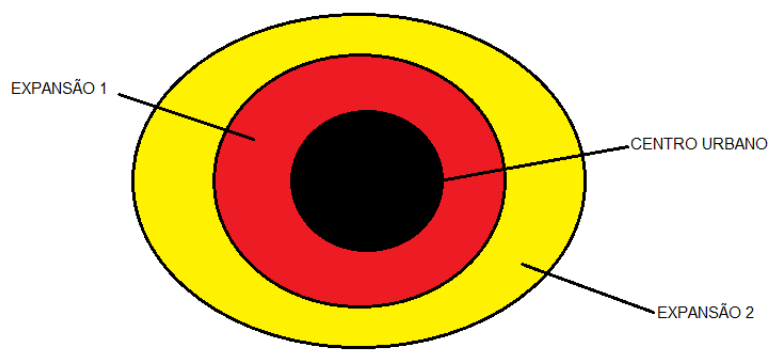

\section{CONCLUSÃO}

O processo de expansão urbana consiste na apropriação do espaço urbano pelo homem em função de suas necessidades. Esse processo pode ser horizontal ou vertical, caracterizando dois tipos distintos de crescimento territorial urbano: crescimento extensivo e intensivo, respectivamente.

Cada tipo de crescimento se apresenta de diferentes formas no tecido urbano. O crescimento intensivo apresenta-se de duas formas: central ou periférica. Já o crescimento extensivo pode se apresentar de cinco formas distintas: (i) por 


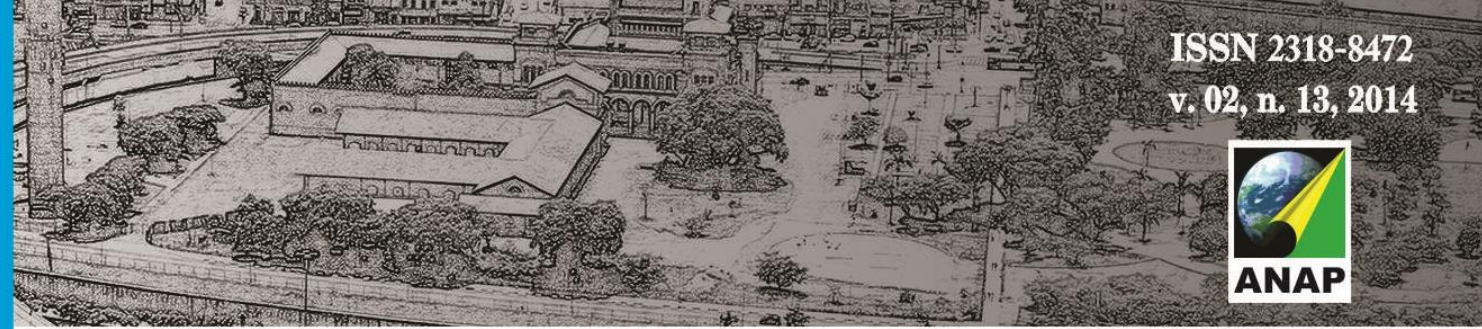

Revista Nacional de

Gerenciamento de Cidades

GRosteIN, M. D. (2001) Metrópole e Expansão Urbana: a Persistência de Processos "Insustentáveis". São Paulo Perspectiva. [online]. Vol.15, n.1, pp. 13-19. ISSN 0102-8839.

LIMONAD, E. (2011) Urbanização dispersa mais uma forma de expressão urbana? Revista Formação, vol. 1, no 14, pp. 31-45.

NASCIMENTO, E.; MATIAS, L. F. (2011) Expansão urbana e desigualdade socioespacial: uma análise da cidade de Ponta Grossa (PR). RA'E GA - O Espaço Geográfico em Análise, ํㅡㄹ 23, pp. 65-97.

PEIXOTO, M. C. D. (2005) Expansão urbana e proteção ambiental: um estudo a partir do caso de Nova Lima/MG. XI Encontro Nacional de Pós-Graduação e Pesquisa em Planejamento Urbano e Regional - ANPUR. Salvador, Bahia.

PORTELLA, A. A. et al. (2013) Segregação social e densidade urbana: o geoprocessamento como instrumento de análise. Anais: Encontros Nacionais da ANPUR, v. 10.

SANTORO, P.F. (2012) Planejar a expansão urbana: dilemas e perspectivas. Tese (Doutorado) Faculdade de arquitetura e Urbanismo de São Paulo, São Paulo.

SANTORO, P.F. (2012) Planejar a expansão urbana: dilemas e perspectivas. Tese (Doutorado) Faculdade de arquitetura e Urbanismo de São Paulo, São Paulo.

SANTOS, L. S. (2012) Expansão urbana, mercado imobiliário e conflitos de terra no Sertão Carioca (1940-1964). Confluenze, vol. 4, no 1, pp. 263-281, Dipartimento di Lingue e Letterature Straniere Moderne, Università di Bologna.

SILVA, et al. (2009) Cartografia da expansão urbana: 1950-2000. VII Congresso da Geografia Portuguesa, Coimbra. 